\title{
Detección de infecciones de transmisión sexual y de cáncer cervino uterino en el CESAMO Las Palmas, San Pedro Sula
}

\author{
Sonia Elizabeth Padilla Escobar' \\ Emelda Ruth Suazo ${ }^{2}$
}

\section{RESUMEN}

En el CESAMO Las Palmas se atienden aproximadamente 100 pacientes diarios, entre los cuales se observó la necesidad de incrementar la toma de citología vaginal para la detección de infecciones de transmisión sexual y el cáncer cervino uterino.

Evaluaciones realizadas a este programa y el análisis de la situación de salud del CESAMO, indican la baja captación y realización de citologías vaginales, debido a factores en la mujer, tales como falta de autocuidado, divulgación y educación, situación económica y pago excesivo de para realizar dicha prueba.

Según estos datos, se había logrado un $35 \%$ de cobertura en el semestre en que se programó la presente investigación.

Entre los hallazgos encontrados en esta investigación, resalta que el $52 \%$ de las mujeres en edad fértil no se realizan la citología vaginal; el $41 \%$ tiene un grado de escolaridad de primaria completa y el $29 \%$ no conocen la importancia de realizarse la citología.

Igualmente, se observó que hubo un incremento significativo de 225 tomas de citología entre los meses de febrero a mayo de 2011, lo cual arrojó la cantidad de 199 resultados del laboratorio, de los cuales se presentó 1 caso de carcinoma escamo celular, 20 de cervicitis por infecciones de transmisión sexual, 36 de tricomoniasis, 4 de cándida albicans y 138 casos normales. Este logro se obtuvo producto de la gestión en la educación para la captación en mujeres en edad fértil; además quedó establecido bajar el costo a Lps. 20.00 por cada prueba y será gratis el día miércoles de cada semana.

Palabras clave: citología vaginal, infecciones de transmisión sexual, cáncer cérvico uterino.

\footnotetext{
${ }^{1}$ Estudiante de Enfermería, Departamento Ciencias de la Enfermería, Escuela Universitaria de Ciencias de la Salud, UNAH-VS; dirección electrónica: soniaescobar_64@hotmail.com.

${ }^{2}$ Asesora, docente del Departamento Ciencias de la Enfermería, Escuela Universitaria de Ciencias de la Salud, UNAH-VS; dirección electrónica: emeldaruthsuazo@yahoo.com
} 


\section{ABSTRACT}

In the CESAMO Las Palmas approximately 100 patients daily demand the attention, identifying the need to increase Pap smear for the detection of sexually transmitted infections and uterine cancer Matterhorn. In this CESAMO programed evaluations, the health situation analysis indicate low uptake and implementation, although the achieved data has 35\% coverage of the semester. Research in vaginal cytology has begun, showing the following factors in women: lack of self-care, lack of outreach and education, overpriced tests.

In accordance with the findings and analysis of this research we announce that $52 \%$ of women of childbearing age have not performed vaginal cytology; $41 \%$ based on complete primary schooling and $29 \%$ do not know its importance. There was a significant increase of 225 cytology tests in the months of February to May 2011, obtaining 199 lab results described as follows: only 1 with squamous cell carcinoma, 20 cervicitis results from sexually transmitted infections, 36 trichomoniasis results, 4 candida albicans results and 138 normal results. This achievement was obtained through the education management uptake in childbearing age women, thus seeking to lower the cost to Lps. 20.00 and free tests on Wednesday of each week.

Key Words: vaginal cytology, sexually transmitted infections, uterine cervical cancer

\section{INTRODUCCIÓN}

Entre los programas de atención en el CESAMO Las Palmas están: control de embarazo, atención puerperal, inmunizaciones, neumología, atención integral de enfermedades prevalentes de la niñez, planificación familiar, manejo sindrómico de infecciones de transmisión sexual, atención del adulto y odontología. Sin embargo, se ha observado y detectado la necesidad de incrementar la toma de muestras de citología vaginal para la detección de infecciones de transmisión sexual y el cáncer cérvico uterino, con la finalidad de brindar una atención adecuada, oportuna y responder así al cumplimiento del tratamiento, seguimiento y manejo oportuno de los riesgos, especialmente en las mujeres.

La falta de conocimiento o descuido de las mujeres que conviven con el flujo vaginal anormal, es uno de los factores de riesgo de mayor frecuencia para el cáncer cérvico uterino, ya que esta patología tiene estrecha asociación con el virus del papiloma humano, razón por la cual amerita realizar una investigación-acción que promueva la participación por parte del investigador y el personal del CESAMO, para mejorar dicho programa de atención, con el objetivo de mejorar las coberturas 
de atención a la mujer en la toma de la citología y prevenir oportunamente las infecciones de transmisión sexual y de cáncer cérvico uterino.

\section{METODOLOGÍA}

Esta investigación-acción tiene un tipo de estudio desde la prospectiva de corte transversal. Su área de estudio se realiza en la unidad de salud Las Palmas, ubicada en el barrio Las Palmas de San Pedro Sula.

Como universo de la investigación se tomará a las mujeres en edad fértil que demanden la atención en la unidad de salud. La muestra se extraerá de los expedientes de las pacientes que fueron atendidas durante el periodo febrero-abril de 2011 y del registro diario-mensual de atenciones, para caracterizar la detección de infecciones y evidenciar el incremento de toma de citología.

\section{RESULTADOS}

De las mujeres que asistieron al CESAMO Las Palmas, el $52 \%$ no se realiza la citología vaginal, es decir, solo el $48 \%$ se la realiza. De ellas, el $31 \%$ cuenta con estudios de primaria completo y el $24 \%$ no se realiza la citología desde hace 2 años, en las edades comprendidas entre 20 a 59 años (ver gráfico 1).

Gráfico 1. Porcentaje de realización de la citología

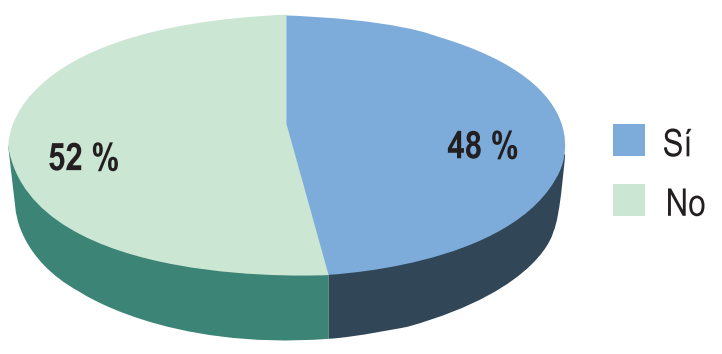


Gráfico 2. Conocimiento e importancia de la citología vaginal

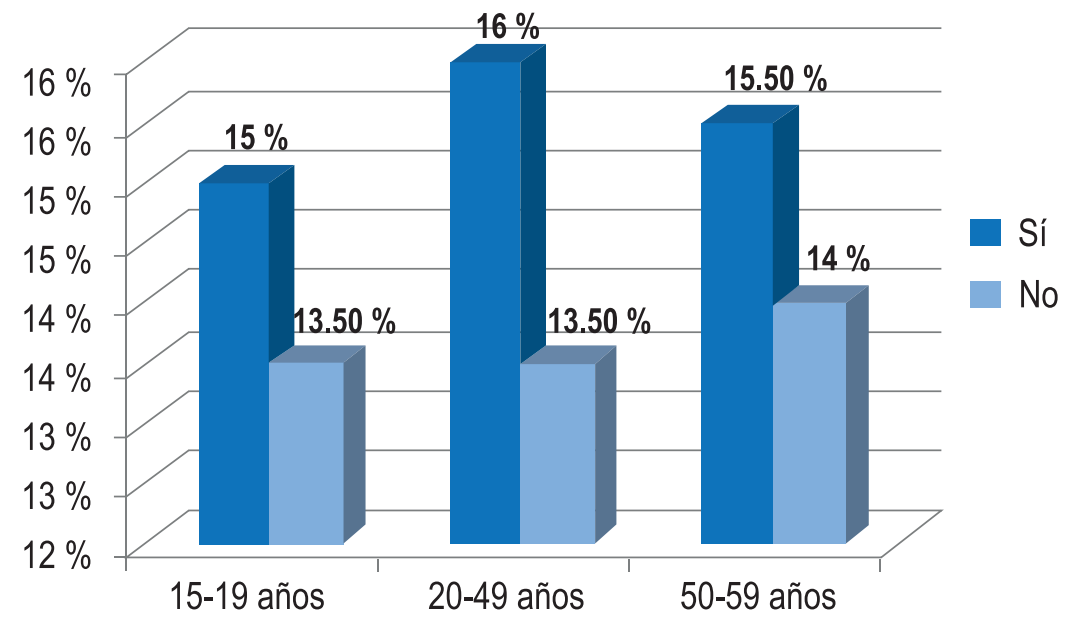

Otro de los hallazgos apunta a que hay un $31 \%$ de mujeres en edades de 15 a 49 años que sí conocen la importancia de realizarse la citología vaginal, pero existe un $27 \%$ en el mismo grupo de edad que consideran no importante hacerse dicho examen (ver gráfico 2).

Igualmente, el $86 \%$ de las mujeres que han padecido infecciones de transmisión sexual se encuentran en los rangos de 15 a 49 años y el $14 \%$ de 50 años y más (ver gráfico 3).

Según el análisis de la toma de citología, que se logró realizar a 225 mujeres en edad fértil, se obtuvieron 199 resultados, de los cuales se detectó el $1 \%$ de cáncer de cérvix, $10 \%$ de cervicitis, $18 \%$ de tricomoniasis, $2 \%$ de cándida albican y $69 \%$ resultados normales.

Para lograr estos datos se realizaron paquetes básicos en las áreas de influenza del CESAMO Las Palmas, con más énfasis en el mes de febrero, lográndose con esta estrategia un incremento en la captación de mujeres, el cual fue del $28 \%$. El $86 \%$ de las edades de las mujeres a las que se logró tomar la citología vaginal, fueron de 20 a 49 años. 
Gráfico 3. Mujeres que han padecido ITS

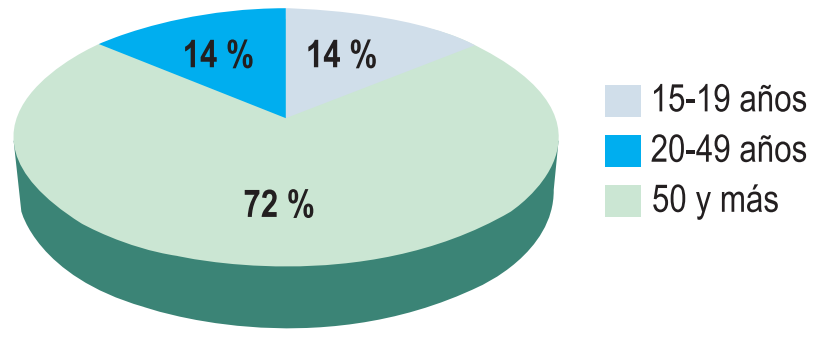

\section{CONCLUSIONES}

Se logró la actualización del análisis de situación de salud del servicio, el cual permitió encontrar la fortaleza y necesidades del mismo, también se incentivaron actividades educativas por parte del personal auxiliar de Enfermería, sobre la importancia de la práctica de la citología vaginal y de esta forma mejorar la detección de infecciones de transmisión sexual.

Otros logros alcanzados son: ofrecer el servicio en las diferentes clínicas de atención, declarar el día miércoles como toma de citologías gratuitas a mujeres en edad fértil, con los resultados de la investigación realizada el personal de enfermería y el resto del personal operativo del CESAMO se comprometió a mejorar la captación de las mujeres en edad fértil para la toma de citología.

\section{BIBLIOGRAFÍA}

Cantarero, H. L. (1997). Manual de normas y procedimientos para la prevención y control del cáncer cérvico uterino. Tegucigalpa: OPS.

Montoya, A. (2003). Guía metodológica, enfermería gestor. Tegucigalpa.

Paredes, M. Manual de manejo de infecciones de transmisión sexual. Tegucigalpa. 